\title{
ANALISIS KEPUASAN PENGUNJUNG TERHADAP LAYANAN PERPUSTAKAAN POLITEKNIK NEGERI BALI
}

\author{
Ni Wayan Dewinta Ayuni' ${ }^{1)}$, Wayan Hesadijaya Utthavi²), dan AA. Istri Raka \\ Wahyuni $^{3)}$ \\ 1,2 Jurusan Akuntansi, Politeknik Negeri Bali, Bukit Jimbaran, Badung,Bali \\ ${ }^{3}$ Unit Perpustakaan, Politeknik Negeri Bali, Bukit Jimbaran, Badung,Bali

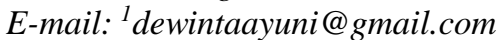

\begin{abstract}
Library can be said as the heart of the universities. Politeknik Negri Bali (PNB) as one of the universities in Indonesia currently has one library room located on the 2nd floor of the PNB Central Building. Based on the data, the average number of PNB library visitors in the year 2017 is only 15\% of the total civitas. This number shows that PNB library has not been optimally utilized. The purpose of this study is to assess the satisfaction of library visitors to $P N B$ library services, so that the PNB library in the future can provide better service and the number of library visitors can increase. The variables used are five service dimensions, namely tangibles, reliability, responsiveness, assurance, and emphaty. The method of analysis used in this study are importance performance analysis (IPA) and analysis of customer satisfaction index (CSI). Results shows that there are some services that need to be maintained, such as the completeness of facilities, updated collection, air circulation, locker safety, convenience in finding references, knowledge of employee, hospitality of employee, concern of employee, response of employee, and good comunication between employee and visitors. According to CSI method, the visitors' satisfaction level is $76,40 \%$ which is classified as satisfied.
\end{abstract}

Keywords: library services, importance performance analysis, customer satisfaction index, politeknik negeri bali

\begin{abstract}
Abstrak
Perpustakaan dapat dikatakan sebagai jantung perguruan tinggi. Politeknik Negeri Bali (PNB) sebagai salah satu perguruan tinggi di Indonesia saat ini memiliki satu ruangan perpustakaan yang bertempat di lantai 2 belakang Gedung pusat PNB. Berdasarkan data, rata-rata jumlah pengunjung perpustakaan PNB tiap bulan di tahun 2017 hanya 15\% dari total civitas. Hal ini menunjukkan bahwa perpustakaan PNB belum dimanfaatkan secara optimal. Tujuan dari penelitian ini adalah untuk mengkaji kepuasan pengunjung perpustakaan terhadap layanan perpustakaan PNB, sehingga perpustakaan PNB ke depannya dapat memberikan layanan yang lebih baik dan jumlah pengunjung perpustakaan dapat meningkat. Variabel yang digunakan adalah lima dimensi jasa, yaitu tangibl), reliability, responsivenss, assurance, dan emphaty. Metode analisis yang digunakan pada penelitian ini adalah impotance performance analysis (IPA) serta analisis customer satisfaction index (CSI). Hasil menunjukkan bahwa terdapat beberapa layanan yang perlu diperbaiki yaitu kelengkapan fasilitas, keterbaruan koleksi, sirkulasi udara, keamanan loker, kemudahan menemukan referensi, pengetahuan petugas, keramahan petugas, kepedulian petugas, respon petugas, dan komunikasi yang baik antara petugas dan pengunjung. Metode CSI menunjukkan tingkat kepuasan pengunjung sebesar 76,40\% atau pada level puas.
\end{abstract}


Kata kunci: layanan perpustakaan, importance performance analysis, customer satisfaction index, politeknik negeri bali

\section{PENDAHULUAN}

Perguruan tinggi sebagai salah satu lembaga Pendidikan tinggi di Indonesia, mengemban tugas yang disebut Tri Dharma Perguruan Tinggi yang meliputi pengajaran, pendidikan, dan pegabdian kepada masyarakat. Dalam mengemban tugas tersebut perguruan tinggi memerlukan suatu fasilitas pendukung yaitu perpustakaan sebagai pusat informasi ilmiah bagi civitas academia perguruan tinggi tersebut (Yunanta, 2015). Perpustakaan merupakan fasilitas pendukung keberhasilan suatu perguruan tinggi dalam menjalankan Tri Dharma Perguruan Tinggi melalui penyediaan, pengorganisasian, dan memerikan pelayanan kepada pengguna perpustakaan (Samosir, 2005). Ahmad dan Abawajy (2014) menyatakan bahwa perpustakaan memainkan peran yang sangat penting dalam menyediakan layanan meliputi penelitian, pengajaran, dan pembelajaran. Keberadaan perpustakaan dapat dikatakan menjadi jantung bagi pendidikan tinggi Undari (2015).

Sesuai dengan fungsinya, perpustakaan harus dapat memberikan pelayanan yang memberikan rasa puas bagi penggunanya, yaitu yang memenuhi kebutuhan dan harapan pengguna (Dharma, Budi, dan Sugata, 2013). Secara sederhana istilah layanan atau service bisa diartikan sebagai melakukan sesuatu bagi orang lain (Tjiptono, 2005). Secara umum, pelayanan pada dasarnya adalah kegiatan yang ditawarkan oleh organisasi atau perorangan kepada konsumen (consumer atau yang dilayani), yang bersifat tidak berwujud dan tidak dapat dimiliki (Prastowo, 2012). Pelayanan pada hakekatnya adalah serangkaian kegiatan dalam proses pemenuan kebutuhan melalui aktifitas orang lain (Yunanta, 2015). Menurut Lupiyoadi (2005) konsumen akan merasa puas jika produk/jasa yang mereka gunakan berkualitas. Pelayanan yang baik dapat memberikan kepuasan terhadap pengguna perpustakaan, sebaliknya jika pelayanan yang diberikan kurang baik maka akan memunculkan kekecewaan pada pengguna perpustakaan. Oleh karena itu, kepuasan pengguna menjadi tolak ukur dalam keberhasilan layanan pepustakaan (Yunanta, 2015).

Model kualitas layanan perpustakaan dikembangkan dan diaplikasikan oleh Parasuraman, Zeithaml, dan Berry menjadi Libqual (Library Quality) (Dharma, Budi, dan Sugata, 2013). Kualitas pelayanan yang dimaksud adalah (1) Tangibles (Bukti fisik); (2) Reliability (pelayanan keandalan);

Responsiveness (pelayanan daya tanggap); (4) Assurance (pelayanan jaminan); dan (5) Empathy (pelayanan empati).

Politeknik Negeri Bali sebagai salah satu perguruan tinggi di Indonesia saat ini memiliki satu ruangan perpustakaan yang bertempat di lantai 2 belakang Gedung pusat Politeknik Negeri Bali. Koleksi perpustakaan PNB berupa Audio visual (CD), buku, handout, laporan penelitian, laporan PKL, tugas akhir, buku referensi, jurnal dan majalah, tabloid, dan surat kabar. Berdasarkan data, rata-rata jumlah pengunjung perpustakaan PNB pada tahun 2017 adalah sebanyak 770 orang tiap bulan. Angka jumlah pengunjung ini hanya $15 \%$ dari total civitas PNB. Hal ini menunjukkan bahwa perpustakaan PNB belum dimanfaatkan secara optimal oleh civitas PNB.

Perpustakaan PNB telah berusaha memberikan layanan yang baik kepada civitas akademika PNB. Namun tentunya layanan tersebut perlu dikaji dari sisi pengguna perpustakaan, apakah layanan yang diberikan telah memberikan 
kepuasan bagi pengguna. Penelitian ini bertujuan mengetahui kepuasan pengunjung perpustakaan terhadap layanan perpustakaan Politeknik Negeri Bali berdasarkan lima dimensi layanan.

\section{METODE PENELITIAN}

Penelitian ini menggunakan metode kuantitatif deskriptif. Populasi pada penelitian ini adalah seluruh civitas akademika PNB. Sampel diambil sebanyak 150 orang pengunjung perpustakaan PNB dengan teknik accidental sampling yaitu pengambilan sampel yang dilaksanakan di perpustakaan PNB.

Variabel yang digunakan pada penelitian ini adalah lima dimensi layanan yaitu (1) Tangibles (Bukti fisik) yaitu fasilitas fisik yang dimiliki perpustakaan seperti gedung, ruangan, buku/koleksi, peralatan, dan sebagainya; (2) Reliability (pelayanan keandalan) yang meliputi kemampuan petugas perpustakaan dalam memberi jasa; (3) Responsiveness (pelayanan daya tanggap) yaitu ketanggapan petugas perpustakaan dalam menanggapi keluhan dan kebutuhan pengguna perpustakaan; (4) Assurance (pelayanan jaminan) yang meliputi keamanan serta rasa aman dari pengguna perpustakaan); dan (5) Empathy (pelayanan empati) yaitu kepedulian petugas perpustakaan terhadap kebutuhan pengguna perpustakaan.

Alat pengukuran data pada penelitan ini menggunaka kuesioner. Sebelum kuesioner digunakan, dilakukan uji validitas dan reliabilitas terhadap kuesioner ini untuk mengetahui kelayakan kuesionel. Uji valitidas dan reliabilitas diterapkan pada 30 sampel penelitian dengan hasil uji validitas dan reliabilitas sebagai berikut:

Tabel 1. Uji Validitas Kuesioner

\begin{tabular}{|c|c|c|c|c|c|}
\hline \multirow{2}{*}{ Dimensi } & \multirow{2}{*}{ Pertanyaan } & \multicolumn{2}{|c|}{ Harapan } & \multicolumn{2}{|c|}{ Kenyataan } \\
\hline & & r -hitung & validitas & r -hitung & validitas \\
\hline \multirow{9}{*}{$\begin{array}{c}\text { Tangible (Bukti } \\
\text { Langsung/Bukti } \\
\text { Fisik) }\end{array}$} & item1 & 0,383 & Valid & 0,590 & Valid \\
\hline & item2 & 0,758 & Valid & 0,474 & Valid \\
\hline & item3 & 0,756 & Valid & 0,503 & Valid \\
\hline & item4 & 0,844 & Valid & 0,735 & Valid \\
\hline & item5 & 0,790 & Valid & 0,597 & Valid \\
\hline & item6 & 0,668 & Valid & 0,629 & Valid \\
\hline & item7 & 0,713 & Valid & 0,642 & Valid \\
\hline & item8 & 0,562 & Valid & 0,729 & Valid \\
\hline & item9 & 0,581 & Valid & 0,607 & Valid \\
\hline \multirow{5}{*}{$\begin{array}{l}\text { Reliability } \\
\text { (Pelayanan } \\
\text { Keandalan) }\end{array}$} & item 10 & 0,969 & Valid & 0,485 & Valid \\
\hline & item11 & 0,937 & Valid & 0,788 & Valid \\
\hline & item12 & 0,857 & Valid & 0,866 & Valid \\
\hline & item13 & 0,899 & Valid & 0,776 & Valid \\
\hline & item14 & 0,969 & Valid & 0,630 & Valid \\
\hline \multirow{3}{*}{$\begin{array}{c}\text { Responsiveness } \\
\text { (Pelayanan Daya } \\
\text { Tanggap) }\end{array}$} & item15 & 0,884 & Valid & 0,853 & Valid \\
\hline & item16 & 0,961 & Valid & 0,769 & Valid \\
\hline & item17 & 0,884 & Valid & 0,826 & Valid \\
\hline \multirow{5}{*}{$\begin{array}{c}\text { Assurrance } \\
\text { (Pelayanan Jaminan) }\end{array}$} & item18 & 0,799 & Valid & 0,744 & Valid \\
\hline & item19 & 0,747 & Valid & 0,602 & Valid \\
\hline & item20 & 0,587 & Valid & 0,366 & Valid \\
\hline & item21 & 0,865 & Valid & 0,551 & Valid \\
\hline & item22 & 0,876 & Valid & 0,538 & Valid \\
\hline
\end{tabular}




\begin{tabular}{cccccc} 
& item23 & 0,553 & Valid & 0,642 & Valid \\
Emphaty (Pelayanan & item24 & 0,721 & Valid & 0,687 & Valid \\
Empati) & item25 & 0,858 & Valid & 0,651 & Valid \\
& item26 & 0,723 & Valid & 0,738 & Valid \\
\hline
\end{tabular}

Sumber: Data Primer yang diolah, Tahun 2018

Tabel tersebut menunjukkan bahwa semua item pertanyaan pada kuesioner telah valid dan dapat digunakan dalam penelitian.

Tabel 2. Uji Reliabilitas Kuesioner

\begin{tabular}{lcccc}
\hline \multirow{2}{*}{ Dimensi } & \multicolumn{2}{c}{ Harapan } & \multicolumn{2}{c}{ Kenyataan } \\
\cline { 2 - 5 } & Cronbach's Alpha & Reliabilitas & Cronbach's Alpha & Reliabilitas \\
\hline Tangible & 0,891 & Reliabel & 0,873 & Reliabel \\
Relablity & 0,974 & Reliabel & 0,874 & Reliabel \\
Responsivenes & 0,957 & Reliabel & 0,902 & Reliabel \\
Assurance & 0,910 & Reliabel & 0,764 & Reliabel \\
Emphaty & 0,856 & Reliabel & 0,831 & Reliabel \\
\hline
\end{tabular}

Sumber: Data Primer yang diolah, Tahun 2018

Hasil analisis uji reliabilitas menunjukkan bahwa semua dimensi penelitian pada kuesioner telah reliabel dan dapat digunakan dalam penelitian. Karena telah lulus uji validtias dan reliabilitas, maka kuesioner dinyatakan layak untuk digunakan sebagai alat pengukuran data pada penelitian ini.

Metode analisis data yang digunakan adalah importance peformance analysis (IPA). Menurut Cugnata dan Salini (2014), tingkat kepentigan (importance) atribut layanan produk atau jasa yang dinilai pengguna merupakan hal yang sangat penting dalam penelitian kepuasan pelanggan/pengguna.

Menurut sejarah, metode Importance Performance Analysis (IPA) pertama kali diteliti oleh Martilla dan James (1977). Metode IPA diawali dengan menghitung nilai kepentingan/harapan (importance) layanan perpustakaan menurut pengguna perpustakaan, lalu mengukur nilai kinerja/kenyataan (performance) layanan perpustakaan yang dinilai oleh pengunjung perpustakaan. Nilai importance dan performance kemudian dipetakan dalam diagram kartesius yang membagi hasil menjadi empat kuadran yaitu kuadran I (keep up the good work/ pertahankan prestasi) kuadran II (possible overkill/ berlebihan), kuadran III (low priority/ Prioritas Rendah), dan kuadran IV (concentrate in here/ prioritas utama). Sedangkan tingkat kepuasan pengunjung perpustakaan diperoleh dengan metode Customer Satisfaction Index (CSI)

\section{HASIL DAN PEMBAHASAN Karakteristik Responden}

Karakteristik responden pada penelitian ini secara ringkas ditampilkan pada Gambar 1.

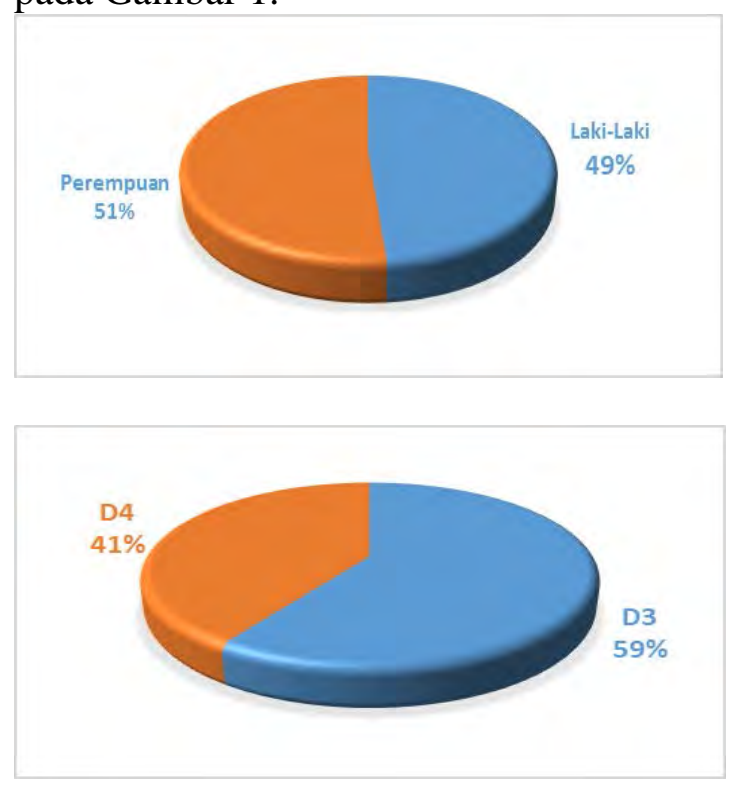




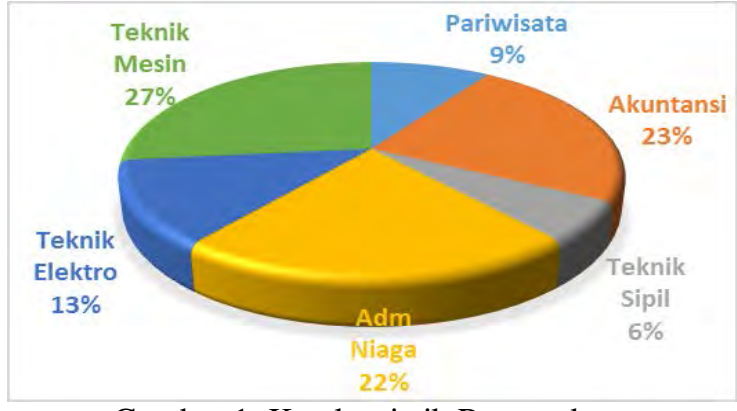

Gambar 1. Karakteristik Responden

Dari gambar tersebut terlihat bahwa berdasarkan jenis kelamin, 51\% responden berjenis kelamin perempuan dan $49 \%$ responden berjenis kelamin lakilaki. Berdasarkan jenjang pendidikanya, terdapat $41 \%$ respnden berjenjang pendidikan D4 dan 59\% berjenjang pendidikan D3. 27\% responden merupakan mahasiswa jurusan Teknik Mesin, 23\% mahasiswa jurusan Akuntansi, 22\% mahasiswa jurusan Administrasi Niaga, 13\% mahasiswa
Teknik Elektro, 9\% mahasiswa jurusan Pariwisata, dan 6\% mahasiswa jurusan Teknik Sipil.

\section{Importance Performance Analysis (IPA)}

Metode Importance Performane Analysis (IPA) ini pada dasarnya mengukur dan membandingkan importance (tingkat kepentingan/ tingkat harapan) atribut yang dinilai oleh responden dan performance (tingkat kinerja/kenyataan) atribut jasa yang diuji. Langkah awal pada metode ini adalah mengukur tingkat kesesuaian antara importance (tingkat kepentingan/ tingkat harapan) dan performance (tingkat kinerja/ kenyataan) setiap atribut pada layanan perpustakaan Politeknik Negeri Bali.

Tabel 3.Tingkat Kesesuaian Importance dan Performance

\begin{tabular}{|c|c|c|c|c|c|}
\hline No & Dimensi & Atribut & $\begin{array}{l}\text { Rata-Rata } \\
\text { Importance }\end{array}$ & $\begin{array}{c}\text { Rata-Rata } \\
\text { Performance }\end{array}$ & $\begin{array}{c}\text { Tingkat } \\
\text { Kesesuaian }\end{array}$ \\
\hline 1 & \multirow{9}{*}{ Tangible } & Kebersihan & 4,61 & 4,01 & 86,99 \\
\hline 2 & & Desain dan Tata Letak & 4,53 & 3,63 & 80,00 \\
\hline 3 & & Fasilitas Lengkap & 4,60 & 3,50 & 76,09 \\
\hline 4 & & Keterbaruan Koleksi & 4,62 & 3,54 & 76,62 \\
\hline 5 & & Kondisi Koleksi & 4,61 & 3,87 & 83,96 \\
\hline 6 & & Kerapian Ruangan & 4,69 & 4,02 & 85,78 \\
\hline 7 & & Sirkulasi Udara & 4,68 & 3,69 & 78,77 \\
\hline 8 & & Kuantitas Koleksi & 4,57 & 3,59 & 78,57 \\
\hline 9 & & Kerapian Pegawai & 4,61 & 4,03 & 87,28 \\
\hline 10 & \multirow{5}{*}{ Reliability } & \multirow{3}{*}{$\begin{array}{l}\text { Kemudahan Administrasi } \\
\text { Kemudahan Prosedur } \\
\text { Peminjaman } \\
\text { Kemudahan Transaksi } \\
\text { Peminjaman/Pengembalian }\end{array}$} & 4,61 & 4,09 & 88,71 \\
\hline 11 & & & 4,66 & 4,09 & 87,70 \\
\hline 12 & & & 4,66 & 4,11 & 88,13 \\
\hline 13 & & Kejelasan Informasi & 4,60 & 3,82 & 83,04 \\
\hline 14 & & Kejelasan Tata Tertib & 4,59 & 3,98 & 86,65 \\
\hline 15 & & $\begin{array}{l}\text { Ketepatan Waktu } \\
\text { Menanggapi Keluhan }\end{array}$ & 4,59 & 3,79 & 82,70 \\
\hline 16 & Responsiveness & $\begin{array}{l}\text { Ketanggapan dalam } \\
\text { Menanggapi Keluhan }\end{array}$ & 4,57 & 3,72 & 81,46 \\
\hline 17 & & $\begin{array}{l}\text { Kesesuaian Pelayanan } \\
\text { dengan Aturan }\end{array}$ & 4,59 & 3,79 & 82,58 \\
\hline
\end{tabular}




\begin{tabular}{|c|c|c|c|c|c|}
\hline 18 & \multirow{5}{*}{ Assurance } & Keamanan dalam Ruangan & 4,67 & 3,96 & 84,86 \\
\hline 19 & & Keamanan dalam Loker & 4,65 & 3,77 & 80,95 \\
\hline 20 & & $\begin{array}{l}\text { Kemudahan menemukan } \\
\text { Referensi }\end{array}$ & 4,63 & 3,71 & 80,00 \\
\hline 21 & & Jumlah Petugas Memadai & 4,58 & 3,91 & 85,30 \\
\hline 22 & & Pengetahuan Petugas & 4,63 & 3,70 & 79,97 \\
\hline 23 & \multirow{5}{*}{ Emphaty } & Keramahan Petugas & 4,66 & 3,75 & 80,54 \\
\hline 24 & & Kepedulian Petugas & 4,65 & 3,75 & 80,52 \\
\hline 25 & & $\begin{array}{l}\text { Respon Petugas yang Baik } \\
\text { Komunikasi antara }\end{array}$ & 4,63 & 3,72 & 80,40 \\
\hline 26 & & $\begin{array}{l}\text { Pengunjung dengan } \\
\text { Petugas }\end{array}$ & 4,64 & 3,79 & 81,61 \\
\hline & & a-Rata & 4,62 & 3,82 & 82,66 \\
\hline
\end{tabular}

Sumber: Data Primer yang diolah, Tahun 2018

Seluruh atribut yang diteliti kemudian dipetakan ke dalam diagram empat kuadran. Empat kuadran ini membagi atribut ke dalam kelompok-kelompok sesuai dengan nilai importance dan performance nya. Diagram kuadran tersebut ditampilkan pada Gambar 2 berikut.

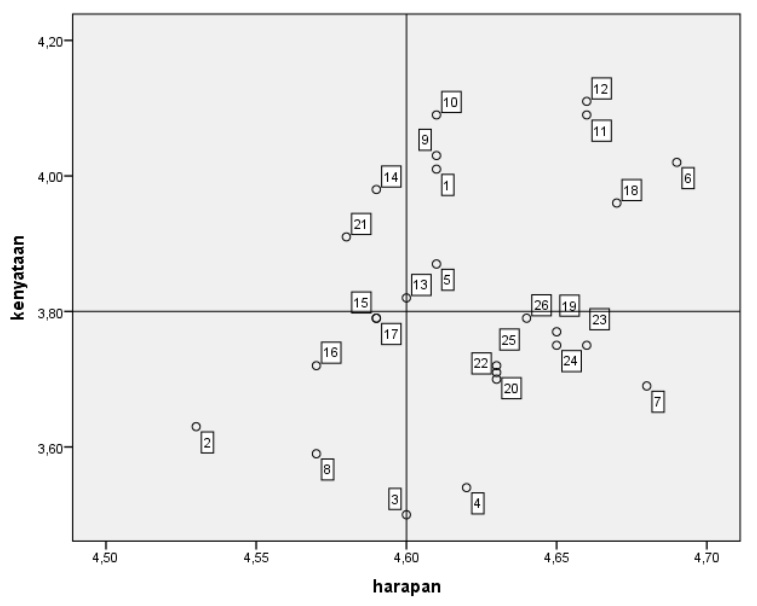

Gambar 2 Kuadran dalam IPA

(Sumber: Data Primer yang diolah, Tahun 2018)

a. Kuadran 1 (Keep Up The Good Work / Pertahankan Prestasi)

Atribut-atribut layanan yang masuk dalam kuadran ini merupakan atribut yang kinerjanya diharapkan tinggi oleh pengunjung perpustakaan dan kenyataannya juga tinggi. Atributatribut yang dimaksud adalah atribut nomor 1 (kebersihan), 5 (kondisi koleksi), 6 (kerapian ruangan), 9 (kerapian pegawai), 10 (kemudahan administrasi), 11 (kemudahan prosedur), 12 (kemudahan transaksi peminjaman/pengembalian), dan 18 (keamanan dalam ruangan). Atributatribut ini diharapkan dapat dipertahankan kinerjanya, dan bila memungkinkan dapat ditingkatkan lagi agar kepuasan pengunjung terhadap kinerja layanan perpustakaan Politeknik Negeri Bali dapat dijaga bahkan ditingkatkan.

b. Kuadran 2 (Possible Overkill / Berlebihan)

Atribut yang berada pada kuadran 2 adalah atribut nomor 4 (kejelasan tata tertib), 13 (kejelasan informasi), dan 21 (jumlah petugas perpustakaan). Atribut-atribut ini kinerjanya diharapkan rendah oleh pengunjung perpustakaan namun pada kenyataannya memiliki kinerja yang tinggi sehingga dapat dianggap berlebihan. Jika fokus perbaikan berada pada atribut ini maka dinilai hanya akan mensia-siakan sumber daya.

c. Kuadran 3 (Low priority/Prioritas rendah)

Kuadran 3 merupakan kuadran di mana kinerja layanan diharapkan rendah dan kinerja kenyataan juga rendah. Atribut-atribut pada kuadran ini perlu ditingkatkan kinerjanya, namun dalam skala prioritas rendah. Pada penelitian ini, atribut yang berada pada kuadran 3 adalah atribut 
nomor 2 (desain dan tata letak), atribut 8 (kuantitas koleksi), 15 (ketepatan waktu dalam menangapi keluhan), 16 (ketanggapan dalam menghadapi keluhan), dan 17 (kesesuaian pelayanan dengan aturan).

d. Kuadran 4 (Concentrate here/Fokus perbaikan)

Kuadran 4 adalah kuadran terpenting karena fokus perbaikan seharusnya dilakukan pada atribut yang berada pada kuadran ini. Atribut yang berada pada kuadran 4 diharapkan memiliki kinerja yang tinggi namun kenyataannya memiliki kinerja yang rendah. Jadi untuk memperbaiki tingkat kepuasan pengunjung, dilakukan perbaikan layanan perpustakaan Politeknik Negeri Bali, khususnya pada atribut pada kuadran ini. Atribut yang dimaksud adalah atribut nomor 3 (kelengkapan fasilitas), 4 (keterbaruan koleksi), 7 (sirkulasi udara), 19 (keamanan dalam loker, 20 (kemudahan menemukan referensi), 22 (pengetahuan petugas), 23 (keramahan petugas, 24 (kepedulian petugas), 25 (respon petugas), dan 26 (komunikasi yang baik antara petugas dan pengunjung).

\section{Customer Satisfaction Index (CSI)}

Selanjutnya, untuk mengukur indeks kepuasan pengunjung perpustakaan secara keseluruhan seperti pada tabel 3 . Berdasarkan hasil analisis t diperoleh nilai customer satisfaction index (CSI) atau indeks kepuasan pengunjung perpustakaan terhadap layanan perpustakaan Politeknik Negeri Bali sebesar 76,40\%. Dalam klasifikasi CSI, angka ini diklasifikasikan puas. Namun walau begitu, tentunya perpustakaan PNB perlu melakukan beberapa perbaikan layanan khususnya atribut-atribut layanan yang masuk dalam kuadran 4 pada analisis IPA. Hal ini perlu dilakukan agar perpustakaan PNB ke depannya dapat memberikan layanan yang lebih baik sehingga indeks kepuasan pengunjung dapat ditingkatkan.

Tabel 3. Customer Satisfaction Index

\begin{tabular}{cllllll}
\hline No & \multicolumn{1}{c}{ Dimensi } & \multicolumn{1}{c}{ Atribut } & MIS & MSS & WF & WS \\
\hline 1 & Kebersihan & 4,61 & 4,01 & 0,0384 & 0,1541 \\
2 & Desain dan Tata Letak & 4,53 & 3,63 & 0,0377 & 0,1368 \\
3 & Fasilitas Lengkap & 4,60 & 3,50 & 0,0383 & 0,1340 \\
4 & Keterbaruan Koleksi & 4,62 & 3,54 & 0,0385 & 0,1361 \\
5 & Tangible & Kondisi Koleksi & 4,61 & 3,87 & 0,0384 & 0,1487 \\
6 & & Kerapian Ruangan & 4,69 & 4,02 & 0,0390 & 0,1568 \\
7 & Sirkulasi Udara & 4,68 & 3,69 & 0,0390 & 0,1436 \\
8 & Kuantitas Koleksi & 4,57 & 3,59 & 0,0381 & 0,1368 \\
9 & Kerapian Pegawai & 4,61 & 4,03 & 0,0384 & 0,1546 \\
\hline 10 & & Kemudahan Administrasi & 4,61 & 4,09 & 0,0383 & 0,1567 \\
11 & Kemudahan Prosedur & 4,66 & 4,09 & 0,0388 & 0,1585 \\
12 & Reliability & Peminjaman & & & & 0,1593 \\
13 & & Kemudahan Transaksi & 4,66 & 4,11 & 0,0388 & 0,1463
\end{tabular}




\begin{tabular}{|c|c|c|c|c|c|c|}
\hline 14 & & Kejelasan Tata Tertib & 4,59 & 3,98 & 0,0382 & 0,1522 \\
\hline 15 & & $\begin{array}{l}\text { Ketepatan Waktu } \\
\text { Menanggapi Keluhan }\end{array}$ & 4,59 & 3,79 & 0,0382 & 0,1448 \\
\hline 16 & Responsiveness & $\begin{array}{l}\text { Ketanggapan dalam } \\
\text { Menanggapi Keluhan }\end{array}$ & 4,57 & 3,72 & 0,0380 & 0,1414 \\
\hline 17 & & $\begin{array}{l}\text { Kesesuaian Pelayanan } \\
\text { dengan Aturan }\end{array}$ & 4,59 & 3,79 & 0,0382 & 0,1450 \\
\hline 18 & & Keamanan dalam Ruangan & 4,67 & 3,96 & 0,0388 & 0,1538 \\
\hline 19 & & Keamanan dalam Loker & 4,65 & 3,77 & 0,0387 & 0,1459 \\
\hline 20 & Assurance & $\begin{array}{l}\text { Kemudahan menemukan } \\
\text { Referensi }\end{array}$ & 4,63 & 3,71 & 0,0386 & 0,1430 \\
\hline 21 & & Jumlah Petugas Memadai & 4,58 & 3,91 & 0,0381 & 0,1489 \\
\hline 22 & & Pengetahuan Petugas & 4,63 & 3,70 & 0,0385 & 0,1425 \\
\hline 23 & & Keramahan Petugas & 4,66 & 3,75 & 0,0388 & 0,1456 \\
\hline 24 & & Kepedulian Petugas & 4,65 & 3,75 & 0,0387 & 0,1451 \\
\hline 25 & Emphaty & $\begin{array}{l}\text { Respon Petugas yang Baik } \\
\text { Komunikasi antara }\end{array}$ & 4,63 & 3,72 & 0,0385 & 0,1433 \\
\hline 26 & & $\begin{array}{l}\text { Pengunjung dengan } \\
\text { Petugas }\end{array}$ & 4,64 & 3,79 & 0,0386 & 0,1462 \\
\hline \multicolumn{3}{|c|}{ Total } & 120,14 & 99,31 & 1 & 3,8202 \\
\hline
\end{tabular}

Sumber: Data primer yang diolah, Tahun 2018

\section{KESIMPULAN DAN SARAN}

Berdasarkan hasil analiss Importance and Performance Analysis (IPA) terdapat beberapa atribut layanan perpustakaan Politeknik Negeri Bali yang memiliki prioritas utama untuk diperbaiki, yaitu kelengkapan fasilitas, keterbaruan koleksi, sirkulasi udara, keamanan dalam loker, kemudahan menemukan referensi, pengetahuan petugas, keramahan petugas, kepedulian petugas, respon petugas, dan komunikasi yang baik antara petugas dan pengunjung. Nilai customer satisfaction index (CSI) pengunjung perpustakaan terhadap layanan perpustakaan PNB sebesar 76,40\% dan termasuk dalam klasifikasi puas.

\section{DAFTAR PUSTAKA}

Ahmad dan Abawajy. (2014). Digital Library Service Quality Assesment Model. Procedia - Social and Behavioral Science, 129 (2014), 571-580.
Cugnata, F, dan Salini, S. 2014. Model based approah for impotance performance analysis. Qual Quant, (2014) 48, 3053-3064.

Dharma,N.O, Budi, N.W.S, dan Sugata,I.G.N. 2013. Hubungan Antara Kualitas Layanan Perpustakaan Undiksha Dan Kepuasan Penggunanya. Jurnal Ilmu Sosial dan Humaniora. Vol 2. No 2. ISSN: 2303-2898

Lupiyoadi, Rambat. (2005). Pemasaran Jasa. Jakarta: Penerbit Salemba Empat.

Martilla, J.A. dan, James, J.C. (1977). Importance-performance analysis. J. Mark. 41(1), 77-79 (1977)

Prastowo, Andi. 2012. Manajemen Perpustakaan Sekolah Profesional. Yogyakarta: DIVA Press

Samosir, Z. (2005). Pengaruh Kualias Pelayanan Terhadap Kepuasan Mahasiswa Mengunaka Perpustakaan USU. Pustaha: Jurnal Studi Perpustakaan dan Informasi. Vol.1 No 1. Juni 2005 
Tjiptono, F. (2005). Service, Quality \& Satisfaction Edisi Ketiga. Yogyakarta: Penerbit Andi.

Undari, Diyah. (2015). “Faktor-Faktor Penentu Kepuasan Mahasiswa

Pendidikan Ekonomi terhadap Pelayanan Perpustakaan di Fakultas Ekonomi Universitas Negeri Semarang.Skripsi. Universitas Negeri Semarang

Yunanta A. (2015). Analisi Kualitas Layanan Perpustakaan Terhadap Kepasan Pengguna Perpustakaan Berdasakan Harapan dan Kenyataan. Studi Kasus Pada Pepustaaan Politeknik Negeri Malang. Tesis. UIN Sunan Kaljaga. Yogyakrta 

Analisis Kepuasan Pengunjung... 